\title{
A NUTRITIONAL ANALYSIS OF THE FOOD BASKET IN BIH: A LINEAR PROGRAMMING APPROACH
}

Almira Arnaut-Berilo, Adela Delalic, Adisa Huseinbasic

\section{Abstract}

This paper presents linear and goal programming optimization models for determining and analyzing the food basket in Bosnia and Herzegovina (BiH) in terms of adequate nutritional needs according to World Health Organization (WHO) standards and World Bank (WB) recommendations. A linear programming $(L P)$ model and goal linear programming model (GLP) are adequate since price and nutrient contents are linearly related to food weight. The LP model provides information about the minimal value and the structure of the food basket for an average person in BiH based on nutrient needs. GLP models are designed to give us information on minimal deviations from nutrient needs if the budget is fixed. Based on these results, poverty analysis can be performed. The data used for the models consisted of 158 food items from the general consumption of the population of BiH according to COICOP classifications, with average prices in 2015 for these products.

Key words: linear programming, goal programming, optimization, cost, nutrition, budget

JEL classification: $C 61$, C82, 131, 132

\section{INTRODUCTION}

Two specialized agencies of the United Nations, the FAO (Food and Agriculture Organization) and WHO (World Health Organization) are making efforts to define international recommendations for the intake of essential nutrients. Estimations of the quality and quantity of food lack for people with compromised nutritional status are based on nutritional needs standards. The results of these estimations can be used for targeting the food supply.

The results also can be used in planning for agricultural production and the creation of national programs, such as, for example, the enrichment of food. The target intake of nutrients for a population is the average intake of certain food components or individual food groups preferable for maintaining health, where health is defined as the low incidence of disease directly associated with food intake. Unlike many
Almira Arnaut-Berilo, $\mathrm{PhD}$

Assistant Professor

School of Economics and Business

University of Sarajevo

E-mail: almira.arnaut@efsa.unsa.ba

Adela Delalic, PhD

Assistant Professor

School of Economics and Business

University of Sarajevo

E-mail: adela.delalic@efsa.unsa.ba

\section{Adisa Huseinbasic}

School of Economics and Business

University of Sarajevo

E-mail: adisa.huseinbasic@student.efsa.unsa.ba 
countries that have set nutrition-based recommendations, $\mathrm{BiH}$ has no such recommendations or studies that address the question of setting nutrition-based recommendations for its citizens.

This is the reason why this study aims to apply linear programming and goal programming optimization models for determining and analyzing the food basket in $\mathrm{BiH}$ using nutritional needs harmonized with the recommendations of the World Health Organization (WHO) and the World Bank (WB). The linear programming (LP) model and goal linear programming model (GLP) are adequate since prices and nutrient content are linearly related to the weight of food items.

The paper is divided into five parts. The literature review provides an overview of the theoretical background and application of linear programming models for analyzing nutrition needs for specific age groups and specific countries. Section 3 explains the data and methodology used for the analysis of the food basket in $\mathrm{BiH}$. The results and analysis are presented in Section 4, which is divided into four main parts: a determination of the absolute minimal daily costs; a determination of minimal daily costs according to the food pyramid; an analysis of the $\mathrm{BiH}$ food basket provided by WB and the creation of an LP model to increase food basket efficiency. Finally, brief summary and concluding remarks are given in Section 5.

\section{LITERATURE REVIEW}

Application of linear programming to analyze food intake is mostly related to cost minimization. There have been many studies that use a linear programming approach focused on countries with extreme poverty or a society's vulnerable groups, such as infants, children, the elderly, people suffering from specific diseases, etc.

Skau, J. et al. (2013) have used linear programming to investigate whether four different complementary food products could contribute to fill nutrient gaps in the local diets for 6-11 month-old Cambodian infants and therefore to ensure an adequate diet. Even though this study has its limitations (a small sample size regarding dietary data, and dietary data collected by using the average recipes of mixed-food dishes, etc.), it emphasized the value of LP for planning a nutritionalintervention program. Darmon, N., Ferguson, E. and Briend, A. (2002) explained the use of linear programming as a method to design nutrient-adequate diets of optimal nutrient density and to identify the most stringent constraints in nutritional recommendations and food consumption patterns in a population's diet in rural Malawi, Africa. This study showed that linear programming can be used to identify dietary patterns and limiting nutrients and to assess whether a nutritionally adequate diet is achievable with locally available foods in different seasons, as well as to identify combinations of foods and portion sizes needed to achieve a nutrient-dense diet and desirable modifications to observed food patterns.

In addition, a certain number of studies analyze the food poverty threshold and recommend methods that enable reducing the population under the poverty threshold, based on an analysis of the food basket. Recommendations are related to specific food items and agricultural activities, Pretty, J.N., et al. (2003); Greer and Thorbecke (1986) and Kyereme and Thorbecke (1987). In this way, Drewnowski, A. and Specter, S.E., (2004) analyzed the relationship between food quality and economic value and the effect of the increase of high energy density food intake as a result of a convenient ratio of cost and energy. The study associates inequality, poverty and education with the increase of inadequate food patterns.

Anderson, A.S et al. (2007) analyzed healthy food baskets without the application of any mathematical model. Instead, the study is based on a qualitative analysis of food (population-based dietary surveys and the current definition of healthy foods by the UK Food Standards Agency). The aim of study was "to develop an objective, nutrient-based, healthy eating indicator shopping basket (HEISB) tool for use in studies of access to healthy food." The final HEISB tool comprised 35 items within the following categories - 17 from fruit and vegetables, nine from potatoes, bread and cereal, five from fish/meats, three from dairy, and one from fatty and sugary foods. The availabilty of food items for the chosen food basket is determined in all Schotland areas, with significant price variations depending of area and sale type, Dawson, J. et al. (2008).

The studies that use LP as a tool to design and analyze food baskets are mainly associated with nutritional food quality. Darmon, N., Ferguson, E.L. and Briend (2002), apart from identifying the lowest cost of a nutiritional diet, also analyzed different uses of LP. They developed an LP model that simulates influences one isolated factor to other variables. The goal function is defined as the sum of relative measures of absolute deviations from the average intake of a food item for corresponding LP variables. They concluded that costs cause an increase of a certain food intake and "added considerable support to the idea that economic constraints are a major factor in determining the nutritional value of foods purchased." By using the same goal function design, Darmon, N., Ferguson, E.L. and Briend (2006) analyzed the influence of cost constraints to food selection and an adequate nutritional 
diet for French women. The study indicates that, without cost constraints, the modeled diet prefers energy from fish, fruits and vegetables. If cost constraints are included, the share of meat, eggs and milk intake is increased. Authors concluded that WHO recommendations are achievable for middle - and upper - income French women, but for those on a low food budget, a different food - based recommendation is required. Rambeloson, Z.J., Darmon, N. and Ferguson, E.L. (2008) used LP to "identify the minimum changes required in the actual donation to achieve the French recommendations." They stated that "French food-bankdelivered food aid does not achieve the French recommendations for dietary fibre, ascorbic acid, vitamin $D$, folate, magnesium, docosahexaenoic acid, a-linolenic acid and the percentage of energy from saturated fatty acids." The study showed that, by using an LP model, these recommendations are achievable if more fruits, vegetables, legumes and fish were collected and less cheese, refned cerals and foods rich in fat, sugar or salt. Oktubo, H. et al. (2015) developed mathematically optimized food intake patterns that met the recommended daily intakes for 28 nutrients studied in each sex and age group (192 healthy Japanese adults aged $31-76$ years divided into two groups $<50$ and $\geq 50$ years). Using a linear programming model they identified optimal food intake patterns providing practical food choices and meeting nutritional recommendations for the Japanese population.

Gerdessen, J.C. and De Vries, J.H.M. (2015) explained the usage of extended goal programming tools in designing diets that are consistent with nutritional, palatability and cost constraints. The authors defined different goal functions and applied them on a diet problem which included 144 foods, 19 nutrients and several types of palatability constraints. Nutritional constraints are modeled with fuzzy sets. The study investigated the sensitivity of results in different models and states that a range of solutions with various properties can be obtained from the same dataset.

In Bosnia and Herzegovina, Pašić, M. et al. (2011) developed a linear programming optimization model of food consumption with minimal costs to meet the daily nutritional needs of the average woman and the average man, in accordance with World Health Organization standards. They have used the 59 most frequent food items gained out of a survey of 50 households as decision variables. Pašić, M. et al. (2012) showed that it is possible to develop a goal programming model with available household budget and at the same time meets required nutritional needs.

\section{THE DATA AND METHODOLOGY}

This paper aims to find the absolute minimal daily food intake costs that meet nutritional needs and to analyze the adequacy of the official BiH food basket provided by the World Bank. Based on the official food basket, linear programming modeling is used to provide a more efficient solution for the food basket. We used World Health Organization recommendations for the daily nutritional needs of average men and women, and price information on 158 food items from the BiH Statistical Agency. The data used for modeling consists of 158 food items from the $\mathrm{BiH}$ consumption expenditure according to a COICOP classification. The food item's average prices in 2015 are used.

The form of the basic model used in this study is:

$$
\begin{gathered}
\min f=c_{1} x_{1}+c_{2} x_{2}+\cdots+c_{n} x_{n} \\
a_{i 1} x_{1}+a_{i 2} x_{2}+\cdots+a_{i n} x_{n} \leq U L(i) \\
a_{i 1} x_{1}+a_{i 2} x_{2}+\cdots+a_{i n} x_{n} \geq R D I(i) \\
x_{j} \geq 0 ; i=\overline{1, m ; j}=\overline{1, n}
\end{gathered}
$$

where, $c i$ - is the average price of the products in $2015 ;-\chi_{i}$ is the 158 food item decision variables $(\eta=158)$. The constraints are UL -Upper daily limits and RDI-Recommended daily intake for nutrients. The daily nutritional needs of average adults are used according to the US Department of Health \& Human Services - NIH (National Institutes of Health) ${ }^{1}$ and incorporated into model constraints. The nutrients that are used in the constraints are divided into three groups: macronutrients, vitamins and minerals. Finally, we formed a model with 54 constraints ( $m=27)$.

Later, according to the goals and requirements of analysis, the basic model is modified. We have developed a goal programming model in order to minimize deviations from nutrients constraints for a fixed budget. The LP model is modified and improved by using the parts of solution obtained by application of the GP model.

\section{RESULTS AND DISCUSSION}

Through the application of linear programming models are determined with the absolute minimal daily costs, the minimal daily costs according to food pyramid, maximal food basket efficiency, and which analyze the official $\mathrm{BiH}$ food basket provided by the WB.

1 https://ods.od.nih.gov/Health_Information/Dietary_Reference_ Intakes.aspx 


\subsection{Determination of absolute minimal daily costs}

We estimated the model with the absolute minimal costs and which satisfied nutritional needs. The resulting food basked is analyzed according to the US Department of Health and Human Services food pyramid (where food items are divided into 6 major groups: 1 . cereals, bread and pasta $40 \%$; 2 . sugar and fat $1-2 \%$; 3. meat, fish and eggs $(12,5 \%) ; 4$. milk and dairy products $(12,5 \%) ; 5$. fruits $(14 \%)$ and 6 . vegetables (20\%)).

The obtained results show that the minimal daily costs for men amount to $1.95 \mathrm{KM}$. However, by analyzing the content of the optimal food basket for the first model, we found that a small number of food items (just 11) are included. Also, by comparing the percentage shares of food groups with the corresponding groups in the food pyramid, we found that the obtained values significantly deviate from those recommended (Figure 1).

Similar results are obtained for women with a minimal daily food cost of $1.84 \mathrm{KM}$ (Figure 2). Again, very few food items are included in the food basket and there is significant deviation from the percentage shares of food groups recommended by the food pyramid.

\subsection{Determination of minimal daily costs according to food pyramid}

In order to improve the first model, we expanded the set of constraints by the percentage shares of food groups recommended by the food pyramid. The models with the exact percentage shares and also with +/$10 \%$ and $+/-20 \%$ from the recommended percentage

Figure 1: Nutritional constraint report and percentage of food groups in optimal LP solution for an average man.

\begin{tabular}{|c|c|c|c|c|c|c|}
\hline \multicolumn{3}{|c|}{ Minimum $C=1,95 \mathrm{KM}$} & UL & RNI & Plan & \multirow{5}{*}{$\begin{array}{l}\text { 1. cereals, bread and pasta } \\
\text { 2. sugar and fat } \\
\text { 3. meat, fish and eggs ) }\end{array}$} \\
\hline \multirow{4}{*}{ 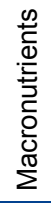 } & Kcal & & 2000 & 3000 & 2417 & \\
\hline & Carbohydrates & g & 347 & 474 & 453,3 & \\
\hline & Feat & g & 42 & 84 & 42 & \\
\hline & Protein & g & 63 & 95 & 63 & \\
\hline \multirow{12}{*}{ 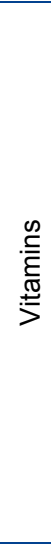 } & A & $\mathrm{mcg}$ & 625 & 3000 & 625 & 4. milk and dairy products \\
\hline & C & $\mathrm{mg}$ & 75 & 2000 & 90,09 & 5. fruits \\
\hline & $\mathrm{D}$ & $\mu \mathrm{g}$ & 10 & 100 & 100 & 6. vegetables \\
\hline & $\mathrm{E}$ & $\mathrm{mg}$ & 12 & 1000 & 13,91 & $1,86 \%$ \\
\hline & K & $\mu \mathrm{g}$ & 120 & NU & 120 & $2,43 \%$ \\
\hline & B1 & $\mathrm{mg}$ & 1 & NU & 3,11 & \\
\hline & B2 & $\mathrm{mg}$ & 1,1 & NU & 1,454 & \\
\hline & B3 & $\mathrm{mg}$ & 12 & 35 & 35 & \\
\hline & B6 & $\mathrm{mg}$ & 1,1 & 100 & 3,92 & \\
\hline & B9 & $\mu g$ & 320 & 1000 & 505,7 & \\
\hline & B12 & $\mu g$ & 2 & NU & 5,083 & \\
\hline & B5 & $\mathrm{mg}$ & 5 & NU & 7,589 & $4,11 \%$ \\
\hline \multirow{10}{*}{ 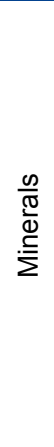 } & $\mathrm{Ca}$ & $\mathrm{mg}$ & 800 & 2500 & 800 & \\
\hline & $\mathrm{Fe}$ & $\mathrm{mg}$ & 6 & 45 & 19,27 & $0,00 \%$ \\
\hline & $\mathrm{Mg}$ & $\mathrm{mg}$ & 350 & 420 & 420 & $73,45 \%$ \\
\hline & $\mathrm{P}$ & $\mathrm{mg}$ & 580 & 4000 & 1372 & \\
\hline & $\mathrm{K}$ & $\mathrm{mg}$ & 4700 & NU & 4700 & \\
\hline & $\mathrm{Na}$ & $\mathrm{mg}$ & 1500 & 2300 & 1500 & \\
\hline & $\mathrm{Zn}$ & $\mathrm{mg}$ & 9,4 & 40 & 9,4 & \\
\hline & $\mathrm{Cu}$ & $\mathrm{mg}$ & 0,7 & 10 & 9,37 & \\
\hline & $\mathrm{Mn}$ & $\mathrm{mg}$ & 2,3 & 11 & 6,394 & \\
\hline & $\mathrm{Se}$ & $\mu \mathrm{g}$ & 45 & 400 & 113,5 & \\
\hline
\end{tabular}

Source: Authors 


\section{Analysis of the BiH food basket provided by the WB}

According to selected nutritional constraints, we have analyzed two $\mathrm{BiH}$ food basket structures provided by the WB. We used the food basket structure given in the "Poverty and Living Conditions" report from the Household Budget Survey 2007. This document doesn't provide a methodology for the selection of food items or a criteria for their corresponding quantities, so we aimed to investigate whether the LP model fits into frame presented or whether it can provide better solution from a nutritional point of view.

Food basket methodology documentation in Montenegro decribes how the selection of the included food items for a food basket, both in Montenegro and other former Yougoslav countries, was inherited from the official statistical agencies of Yougoslavia. The food basket consisted of 66 food items. Reaserch on a food basket including 156 food items was conducted in Montenegro. It concluded that over $90 \%$ of consumption was associated with 54 items, all of which were already included in a previous list of 66 food items. This is the one of probable reasons why the WB recommends a food basket of 66 food items for $\mathrm{BiH}$.

In the abovementioned document, "Poverty and Living Conditions", two different food basket structures are given: the first is named the "starting food basket," and the second the "optimal food basket." This list of food items is different from that which we obtained under the COICOOP classification, so it was necessary to make certain adjustments. Based on the LP model, we obtained minimal costs with the suggestions of the structures of "food basket 1" and "food basket 2".

The results for an average man are given in Table 2 . In the first food basket, minimal costs amount to 3.54 $\mathrm{KM}$, but not all of the constraints are met. For example, in the case of an adult man, there are deficiencies in the adequate intake of vitamins B12 and B5, and also Calcium, Magnesium, Sodium and Potassium. It can

Table 2: Minimal costs with constraint analysis of the WB suggestions of "food basket 1" for average man.

\begin{tabular}{|c|c|c|c|c|c|c|}
\hline men & \multicolumn{2}{|c|}{ 3,54 KM } & RDI & UL & Food basket & intake \\
\hline \multirow{4}{*}{ 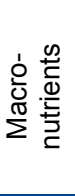 } & Kcal & & 2000 & 3000 & 2000,00 & ok \\
\hline & Carbohydrates & g & 347 & 474 & 307,00 & lower limit \\
\hline & Feat & $g$ & 42 & 84 & 66,15 & ok \\
\hline & Protein & $g$ & 63 & 95 & 51,09 & lower limit \\
\hline \multirow{12}{*}{ 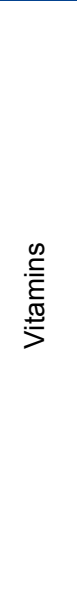 } & A & $\mathrm{mcg}$ & 625 & 3000 & 1953,26 & ok \\
\hline & C & $\mathrm{mg}$ & 75 & 2000 & 65,43 & lower limit \\
\hline & $\mathrm{D}$ & $\mu \mathrm{g}$ & 10 & 100 & 19,02 & ok \\
\hline & $E$ & $\mathrm{mg}$ & 12 & 1000 & 13,17 & ok \\
\hline & $\mathrm{K}$ & $\mu g$ & 120 & NU & 169,16 & ok \\
\hline & B1 & $\mathrm{mg}$ & 1 & $\mathrm{NU}$ & 3,59 & ok \\
\hline & B2 & $\mathrm{mg}$ & 1,1 & NU & 2,16 & ok \\
\hline & B3 & $\mathrm{mg}$ & 12 & 35 & 25,96 & ok \\
\hline & B6 & $\mathrm{mg}$ & 1,1 & 100 & 1,59 & ok \\
\hline & B9 & $\mu g$ & 320 & 1000 & 428,32 & ok \\
\hline & B12 & $\mu \mathrm{g}$ & 2 & NU & 1,67 & lower limit \\
\hline & B5 & $\mathrm{mg}$ & 5 & NU & 2,33 & lower limit \\
\hline \multirow{10}{*}{ 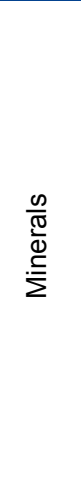 } & $\mathrm{Ca}$ & $\mathrm{mg}$ & 800 & 2500 & 584,94 & lower limit \\
\hline & $\mathrm{Fe}$ & $\mathrm{mg}$ & 6 & 45 & 22,65 & ok \\
\hline & $\mathrm{Mg}$ & $\mathrm{mg}$ & 350 & 420 & 203,00 & lower limit \\
\hline & $\mathrm{P}$ & $\mathrm{mg}$ & 580 & 4000 & 783,38 & ok \\
\hline & $\mathrm{K}$ & $\mathrm{mg}$ & 4700 & NU & 1541,69 & lower limit \\
\hline & $\mathrm{Na}$ & $\mathrm{mg}$ & 1500 & 2300 & 1266,62 & lower limit \\
\hline & $\mathrm{Zn}$ & $\mathrm{mg}$ & 9,4 & 40 & 5,96 & lower limit \\
\hline & $\mathrm{Cu}$ & $\mathrm{mg}$ & 0,7 & 10 & 3,08 & ok \\
\hline & $\mathrm{Mn}$ & $\mathrm{mg}$ & 2,3 & 11 & 3,62 & ok \\
\hline & $\mathrm{Se}$ & $\mu \mathrm{g}$ & 45 & 400 & 82,45 & ok \\
\hline
\end{tabular}

Source: Authors 
be investigated whether the permanent lack of these nutrients can cause certain diseases.

In the second model, the minimal costs are 3.21 $\mathrm{KM}$ and, in several cases, exceeded the lower or upper limits. Table 3 presents the results from the second model.

Again, there are lacks in the adequate intake of $\mathrm{E}$ vitamin, Calcium, Magnesium and Potassium, and an excessive intake of vitamins A and B3 and Sodium.

\subsection{Creation of an LP model to increase food basket efficiency}

In the end, based on the LP model, we suggested a more efficient food basket structure that would meet all constraints with lower costs. We have modified the LP model constraints by including restrictions related to variables or sets of variables according to the structure of the food basket suggested by the WB. We also used the results of the GP model obtained on the basis of a fixed budget to modify the constraints of the LP model in order to minimize deviation from the original food basket. The results of the GP model offer different structures for food baskets according to constraints and a pre-defined budget. For all of these different food baskets we have analyzed the structure related to the food pyramid, and selected a food basket with a budget of $3.54 \mathrm{KM}$. This is the same budget that we calculated in "food basket 1" (Table 2) except that we offer a different food basket structure. Our food basket meets the nutritional requirements for an average man. The resulting food basket, presented in Table 4, follows the structure of the " 66 item" food basket, costs $3.54 \mathrm{KM}$ on a daily basis and satisfies all of the recommended nutritional needs.

Table 3: Minimal costs with constraint analysis of the WB suggestions of "food basket 2" for average man.

\begin{tabular}{|c|c|c|c|c|c|c|}
\hline men & \multicolumn{2}{|c|}{ 3,21 KM } & RDI & UL & Food basket & intake \\
\hline \multirow{4}{*}{ 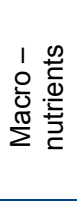 } & Kcal & & 2000 & 3000 & 2247,52 & ok \\
\hline & Carbohydrates & $g$ & 347 & 474 & 360,45 & ok \\
\hline & Feat & $g$ & 42 & 84 & 57,73 & ok \\
\hline & Protein & $g$ & 63 & 95 & 74,58 & ok \\
\hline \multirow{12}{*}{ 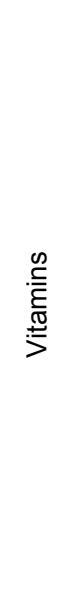 } & $A$ & $\mathrm{mcg}$ & 625 & 3000 & 4831,09 & upper limit \\
\hline & $\mathrm{C}$ & $\mathrm{mg}$ & 75 & 2000 & 104,91 & ok \\
\hline & $\mathrm{D}$ & $\mu g$ & 10 & 100 & 17,31 & ok \\
\hline & $E$ & $\mathrm{mg}$ & 12 & 1000 & 9,24 & lower limit \\
\hline & $\mathrm{K}$ & $\mu g$ & 120 & $\mathrm{NU}$ & 123,67 & ok \\
\hline & B1 & $\mathrm{mg}$ & 1 & NU & 4,34 & ok \\
\hline & B2 & $\mathrm{mg}$ & 1,1 & NU & 4,38 & ok \\
\hline & B3 & $\mathrm{mg}$ & 12 & 35 & 40,57 & upper limit \\
\hline & B6 & $\mathrm{mg}$ & 1,1 & 100 & 2,41 & ok \\
\hline & B9 & $\mu g$ & 320 & 1000 & 751,07 & ok \\
\hline & B12 & $\mu g$ & 2 & NU & 44,63 & ok \\
\hline & B5 & $\mathrm{mg}$ & 5 & NU & 6,86 & ok \\
\hline \multirow{10}{*}{ 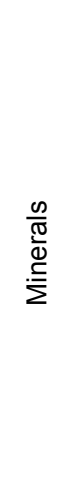 } & $\mathrm{Ca}$ & $\mathrm{mg}$ & 800 & 2500 & 620,81 & lower limit \\
\hline & $\mathrm{Fe}$ & $\mathrm{mg}$ & 6 & 45 & 28,36 & ok \\
\hline & $\mathrm{Mg}$ & $\mathrm{mg}$ & 350 & 420 & 243,54 & lower limit \\
\hline & $P$ & $\mathrm{mg}$ & 580 & 4000 & 1219,31 & ok \\
\hline & $\mathrm{K}$ & $\mathrm{mg}$ & 4700 & NU & 2138,07 & lower limit \\
\hline & $\mathrm{Na}$ & $\mathrm{mg}$ & 1500 & 2300 & 5306,80 & upper limit \\
\hline & $\mathrm{Zn}$ & $\mathrm{mg}$ & 9,4 & 40 & 9,70 & ok \\
\hline & $\mathrm{Cu}$ & $\mathrm{mg}$ & 0,7 & 10 & 11,02 & upper limit \\
\hline & $\mathrm{Mn}$ & $\mathrm{mg}$ & 2,3 & 11 & 4,41 & ok \\
\hline & $\mathrm{Se}$ & $\mu \mathrm{g}$ & 45 & 400 & 131,49 & ok \\
\hline
\end{tabular}

Source: Authors 
Table 4: Food basket optimal structure based on LP model.

\begin{tabular}{|c|c|c|c|}
\hline Food items & $\begin{array}{l}\text { Quantity (kg per } \\
\text { month per person) }\end{array}$ & Food items & $\begin{array}{l}\text { Quantity (kg per month } \\
\text { per person) }\end{array}$ \\
\hline Rice & 0,1712 & Salt & 0,148737 \\
\hline Other grains & 0,744 & Coffee & 0,1304 \\
\hline Wheat flour (all types) & 3,96 & Fruit syrup, fruit juices & 0,2328 \\
\hline Other flour & 0,216 & Beer & 0,6616 \\
\hline Bread & 2,9 & Fresh citrus fruits & 0,330432 \\
\hline Pasta & 0,284 & Bananas & 0,12 \\
\hline Biscuits, confectionery & 0,106316 & Apples & 0,2352 \\
\hline Beef, veal & 0,328 & Pears & 0,0928 \\
\hline Poultry (fresh, or frozen) & 0,3864 & Grapes & 0,0832 \\
\hline Other products of animal origin & 0,04 & Nuts & 0,072 \\
\hline Freshwater and saltwater fish & 1,053625 & Other fruits (strawberries, ...) & 0,1504 \\
\hline Other fish products & 0,04 & Walnuts, almonds ... & 0 \\
\hline Fresh milk & 4,554308 & Dried fruits & 0,0376 \\
\hline Yogurt and sour milk, & 0,6168 & Leafy fresh vegetables & 1,519994 \\
\hline Sour cream & 0,1816 & Cabbages & 0,392 \\
\hline Cream cheese & 0,2296 & Tomato & 0,2664 \\
\hline White cheese & 0,1808 & Pepper & 0,2104 \\
\hline Eggs & 0,192 & Cucumber & 0,1664 \\
\hline Butter & 0,072 & Peas and beans & 0,0512 \\
\hline Margarine, shortening & 0,0792 & Dried beans & 2,441595 \\
\hline Cooking oil & 0,56 & Carrot & 0,072 \\
\hline Other animal fat & 0,2536 & Onions & 0,1704 \\
\hline Sugar & 0,6168 & Garlic & 1,119706 \\
\hline Jam, jelly & 0,1128 & Potato & 23,35035 \\
\hline $\begin{array}{l}\text { Other confectionery products } \\
\text { (ice cream, ...) }\end{array}$ & 0,04 & Other fresh vegetables & 0,665716 \\
\hline Vinegar & 0,0616 & Processed and canned vegetables & 0,159474 \\
\hline
\end{tabular}

\section{Source: Authors}

Figure 3: Percentage of food groups in optimal food basket obtained by LP.

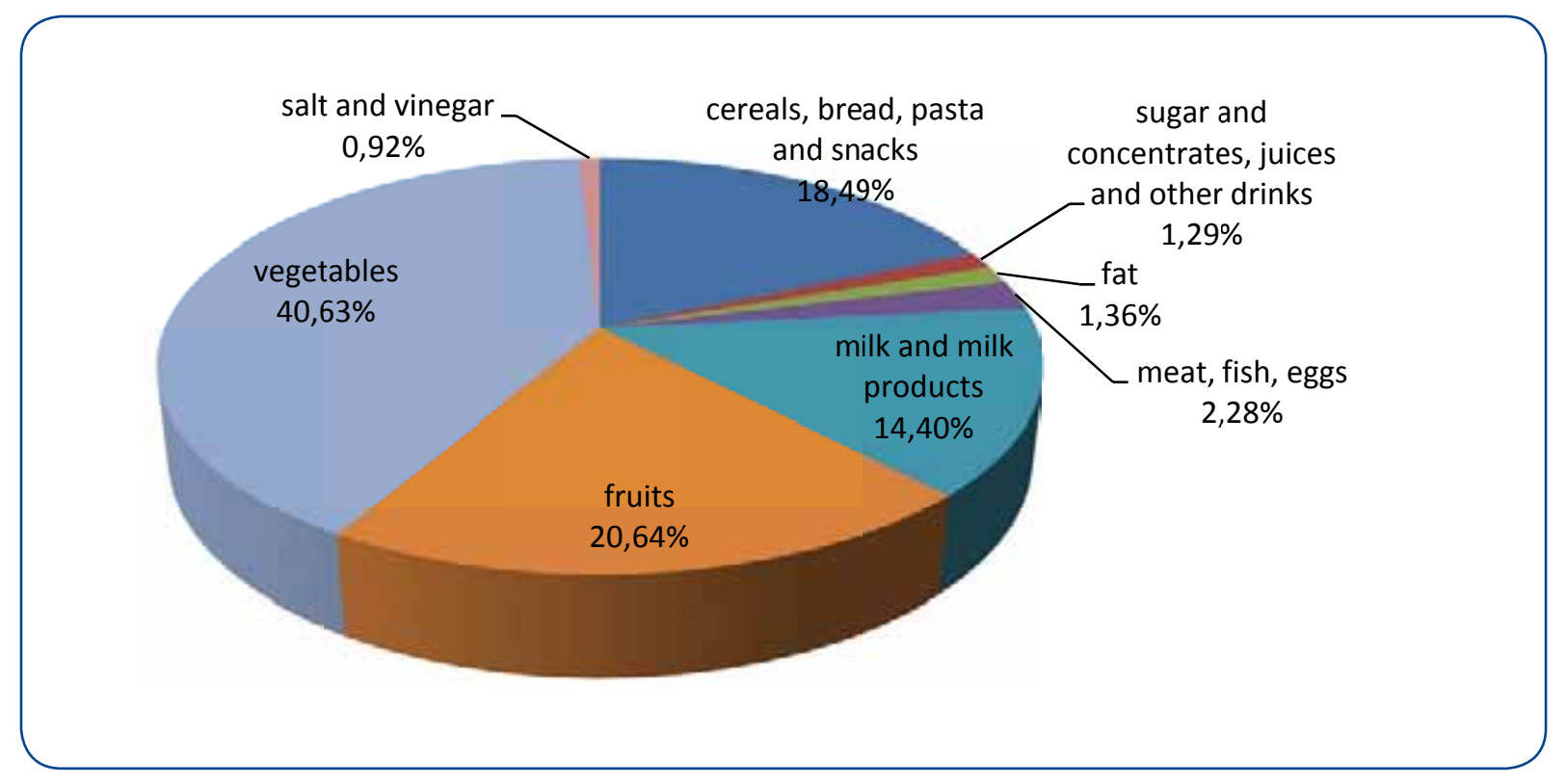

Source: Authors 
The resulting food basket follows the structure of the food pyramid more efficiently than the food basket from the first model (Figure 2).

Note that the structure of the food basket follows the list of food items contained in the document "Poverty and Living Conditions" report from the Household Budget Survey 2007, from the BiH Statistical Agency. In this document, certain groups of products are classified into groups or not listed. For example, no. 36 is coffee, while numbers 37,38 are omitted, and in the original list should be tea and cocoa.

\section{CONCLUSION}

This paper analyzes the food basket, aiming to minimize daily food costs while satisfying recommended nutritional daily requirements. A few LP models were created and the results showed that the minimal daily food costs in $\mathrm{BiH}$ were $1.95 \mathrm{KM}$ for the average man and $1.84 \mathrm{KM}$ for the average woman. The structure of the optimal food basket contained approximately $74 \%$ vegetables. Therefore, an additional request regarding adherence to the food pyramid structure was included. In the sequel, instead of the food pyramid, the structure of the food basket provided by World Bank was used. For the proposed two food baskets (starting and optimal), determined LP models had resulted showing daily food costs of $3.21 \mathrm{KM}$ and 3.54 $\mathrm{KM}$, while nutritional constraints were not met. The LP model was modified in several ways and the GP model was introduced in order to minimize deviation from the proposed food basket proposition with nutritional needs met. The results were included into a modified LP model and the optimal food basked resulted in daily food costs of $3.54 \mathrm{KM}$, with all nutritional needs satisfied.

Specifically for $\mathrm{BiH}$ we can see that the food basket consists of a large percentage of vegetables and fruits, and cost reduction is achieved by increasing the percentage of vegetables. We found that a food basket that can satisfy nutrition demands for a healthy diet can be created even below the extreme poverty line (according to EU commission data, the extreme poverty line is $1 \$$ to $2.15 \$^{2}$ ). We believe that this result can be used in the poverty analysis in Bosnia and Herzegovina (for the analysis of the adequacy of a nutritional poverty threshold or in determining the

2 The \$1 per day concept came from collecting together the standards used by 15 of the world's poorest countries and for the CEE/CIS countries the World Bank has suggested an absolute poverty line of \$2.15, Manuscript European Commission (2011), http:// ec.europa.eu/social/ size and causes of extreme poverty results), and that this result can be used in the planning of agricultural production.

Methodologically, this paper brings a new and different application of LP to nutrition basket analysis. The LP model has been transformed according to GP logic, so that the previous LP goal function has become a budget constraint and the new goal function is defined as the minimum deviation from the previously given values. In our case this was the structure of the food basket, which was known in advance. This research is mainly quantitative and we believe that the qualitative aspect with the appropriate involvement of nutritionist experts will lead to improved research.

\section{REFERENCES}

Anderson, A.S., Dewar, J., Marshall, D., Cummins, S., Taylor, M., Dawson, J. and Sparks, L., 2007. The development of a healthy eating indicator shopping basket tool (HEISB) for use in food access studies-identification of key food items. Public health nutrition, 10(12), pp.1440-1447.

Darmon, N., Ferguson, E.L. and Briend, A., 2002. A cost constraint alone has adverse effects on food selection and nutrient density: an analysis of human diets by linear programming. The Journal of nutrition, 132(12), pp.3764-3771.

Darmon, N., Ferguson, E.L. and Briend, A., 2006. Impact of a cost constraint on nutritionally adequate food choices for French women: an analysis by linear programming. Journal of nutrition education and behavior, 38(2), pp.82-90.

Darmon, N., Ferguson, E. and Briend, A., 2002. Linear and nonlinear programming to optimize the nutrient density of a population's diet: an example based on diets of preschool children in rural Malawi. The American journal of clinical nutrition, 75(2), pp.245-253.

Dawson, J., Marshall, D., Taylor, M., Cummins, S., Sparks, L. and Anderson, A.S., 2008. Accessing healthy food: availability and price of a healthy food basket in Scotland. Journal of Marketing Management, 24(9-10), pp.893-913.

Drewnowski, A. and Specter, S.E., 2004. Poverty and obesity: the role of energy density and energy costs. The American journal of clinical nutrition, 79(1), pp.6-16.

Gerdessen, J.C. and De Vries, J.H.M., 2015. Diet models with linear goal programming: impact of achievement functions. European journal of clinical nutrition, 69(11), pp.1272-1278.

Greer, J. and Thorbecke, E., 1986. A methodology for measuring food poverty applied to Kenya. Journal of Development Economics, 24(1), pp.59-74. 
Kyereme, S.S. and Thorbecke, E., 1987. Food poverty profile and decomposition applied to Ghana. World Development, 15(9), pp.1189-1199.

Okubo, H., Sasaki, S., Murakami, K., Yokoyama, T., Hirota, N., Notsu, A., Fukui, M. and Date, C., 2015. Designing optimal food intake patterns to achieve nutritional goals for Japanese adults through the use of linear programming optimization models. Nutrition journal, 14(1), p.1.

Pasic, M., Catovic, A., Bijelonja, I. and Crnovrsanin, S., 2011, January. Linear programming local cost nutrition optimization model. In Annals of DAAAM for 2011 \& Proceedings of the 22nd International DAAAM Symposium (pp. 0389-0390).

Pasic, M., Catovic, A., Bijelonja, I. and Bahtanovic, A., 2012. Goal Programming Nutrition Optimization Model. In Proceeding of the 23rd International DAAM Symposium Volume23 (No. 1).

Pretty, J.N., Morison, J.I. and Hine, R.E., 2003. Reducing food poverty by increasing agricultural sustainability in developing countries. Agriculture, ecosystems \& environment, 95(1), pp.217-234.

Rambeloson, Z.J., Darmon, N. and Ferguson, E.L., 2008. Linear programming can help identify practical solutions to improve the nutritional quality of food aid. Public health nutrition, 11(04), pp.395-404.

Skau, J.K., Bunthang, T., Chamnan, C., Wieringa, F.T., Dijkhuizen, M.A., Roos, N. and Ferguson, E.L., 2014. The use of linear programming to determine whether a formulated complementary food product can ensure adequate nutrients for 6-to 11-month-old Cambodian infants. The American journal of clinical nutrition, pp.ajcn-073700.

European Commission, Directorate-General for Employment, Social Affairs and Inclusion, Manuscript completed in January 2011, The measurement of extreme poverty in the european union, http://ec.europa. eu/social/BlobServlet?docld=6462\&langld=en (accesed: 13. 03. 2017).

Metodologija izrade minimalne potrošačke korpe, Zavod za statistiku Crne Gore

https://www.monstat.org/userfiles/file/min\%20potrosacka/metodologija\%20MPK\%2020_04.pdf (accesed: 13. 03. 2017.)

Poverty and Living Conditions - report from the Household Budget Survey 2007, BiH Statistical Agency; http://www. bhas.ba/ankete/hbs_07_001-bh.pdf: (accesed: 20. 06. 2016.)

https://ods.od.nih.gov/Health_Information/Dietary_ Reference_Intakes.aspx (accesed: 20. 06. 2016.)

http://nutritiondata.self.com/facts/sausages-and-luncheon-meats/1365/2 (accesed: 20. 06. 2016.)

http://www.foodnutritiontable.com/nutritions/nutrient /?id=693 (accesed: 20.06 .2016 .) 